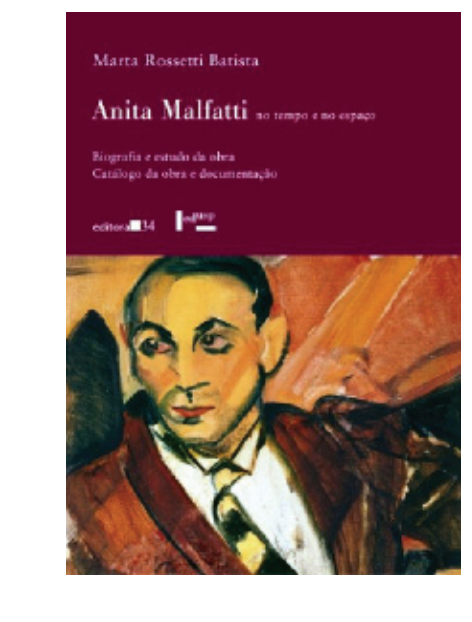

\title{
ANITA MALFATTI NO TEMPO E NO ESPAÇO
}

ROSSETti Batista, Marta. São Paulo:

EDITORA 34/EDUSP, 2006, 840p.

ISBN: $978-85-73263-70-\mathrm{I}$

Júlio Roberto Katinsky

\section{Anita malfatti DE MARTA ROSSETti BATISTA}

O livro de Marta Rossetti Batista, intitulado: Anita Malfatti no tempo e no espaço, compõe-se de dois volumes: o primeiro trata da "Biografia e estudo da obra"; o segundo é um "Catálogo da obra e documentação". Este último apresenta, além de introdução da autora e uma bibliografia, o inventário de cerca de 1.000 obras; mas, como adverte a autora, não pode ser considerado terminado, pois devem estar ainda esquecidas, em alguma gaveta ou fundo de armário, obras que a artista subestimou ou mesmo seus familiares. As obras recolhidas são acompanhadas de catalogação, de acordo com as normas estabelecidas, sua localização quando foram expostas, e às vezes, de alguns comentários. Raríssimos artistas brasileiros podem contar com um trabalho tão minucioso e conduzido com tanto zelo. Acresce que, iniciado em 1964, em uma bolsa de iniciação científica da Fapesp, sob a orientação e responsabilidade do professor Flavio Motta, prosseguiu por iniciativa da pesquisadora, sendo publicado em dezembro de 2006.

Entretanto, eu acrescentaria um ano a esse período. Na realidade, a pesquisa começou em 1963, com planejamento do estudo da obra de Anita, Tarsila Amaral e Flavio de Carvalho, tendo Flavio Motta se encarregado das primeiras propostas de catalogação da obra de Candido Portinari, desaparecido no ano anterior. Pouco tempo depois, seu filho, Antonio Candido, iniciou o inventário do grande pintor brasileiro.

No caso de Anita Malfatti, são 43 anos de pesquisa, quase tanto tempo quanto de vida artística da pintora brasileira se, arbitrariamente, estabelecermos o período de 1914 (quando voltou da Alemanha) até 1964 quando morreu, ou seja, 50 anos; graças a esse trabalho, podemos usufruir de uma visão bem mais precisa da contribuição da artista paulista para a cultura brasileira do século 20, 
do que a maior parte de seus contemporâneos. Entretanto, esse trabalho, conduzido sem auxílios, ou incentivos financeiros, não pode ser explicado profissionalmente: é, antes de tudo, um milagre afetivo.

O primeiro livro, a biografia da artista, apresenta a mesma minuciosa busca de comprovações documentais, mas agora temos um vasto painel no qual se articulam a vida de uma paulistana nascida nos finais do século 19, dentro de uma família de classe media alta, com parentes excepcionalmente escolarizados para o tempo e lugar, uma cidade provinciana e consciente de seu provincianismo e, portanto, sedenta de transformações que a colocasse no mesmo patamar, pelo menos, da capital da república, e mais, quem sabe, das grandes cidades de nossa "civilização" ocidental, cientifica e tecnologicamente, com uma indústria que estava em vias de suplantar a maior cidade industrial brasileira, Rio de Janeiro.

$\mathrm{E}$, finalmente, mas não menos importante, novas preocupações com as artes, bem atestadas pelo lançamento de um teatro oficial (Municipal!) em 1908, antes mesmo que a própria capital da República cogitasse, com recursos federais, de construir o seu.

Marta, discretamente, poucas referências faz aos acontecimentos sociais que abalaram o mundo e o país, bem como trata com isenção as perturbações daquele século tão revolucionado e que se prolonga pelo início deste século.

Todos os autores que trataram de Anita Malfatti, de maneira mais suave ou mais áspera, colocam-na como figura central de uma espécie de terremoto cultural, com sua exposição de 1917, na qual ela exibiu pinturas criadas na Alemanha e Estados Unidos até 1916.

Parece ter havido um consenso entre amigos e inimigos de o choque provocado por essas pinturas abalar não só o "bem comportado" ambiente cultural paulistano, mas sua reação pelos elementos mais conservadores, prejudicar, definitivamente, o desenvolvimento posterior da pintora.

Um dos méritos, e não pequeno, do livro de Marta, é registrar, inequivocamente, um aspecto dessa artista e apresentar uma grande homogeneidade em sua longa carreira artística. Pode-se acompanhar, ao longo de todos os anos, o desenvolvimento de seu desenho, como atividade artística autônoma, mesmo que ela não desse muita atenção a ele.

O século 20, parece, foi o século da arquitetura e do desenho no Brasil, mais do que da pintura e escultura. Desenho, entendida como tal também a gravura. Ainda que apoiado em experiências européias e norte-americanas, o desenho brasileiro, principalmente a partir da caricatura, cedo se torna autônomo como meio expressivo e, no ato, firma-se como atividade artística autônoma, independente de sua condição de suporte de outras atividades artísticas - pintura, por exemplo, que na Itália é conhecido como "sinopia".

Como é sabido, o desenho, lentamente, adquiriu, com a caricatura, a condição de "arte maior" na Europa. E, no Brasil, no século 20. Pois, examinando os documentos recolhidos por Marta Rossetti Batista, verificamos que as apreciações críticas sobre sua pintura não valem para seu desenho. Como, aliás, para sua companheira de jornada mais próxima, Tarsila do Amaral. Um dos grandes méritos da exposição de 1969, no MAM do Rio de Janeiro, com curadoria da senhora Aracy do Amaral, foi justamente tornar pública uma 
enorme coleção de desenhos da artista, até então praticamente desconhecidos. Também, nesse caso, revelou-se um acervo homogêneo de obras, sem hesitações, sem saltos, e de uma qualidade que assegura as ambas, Anita e Tarsila, uma posição de destaque entre os artistas brasileiros do século 20. Os jornais de São Paulo noticiaram o grande empenho em realizar o primeiro inventário com adequados recursos, da obra de Tarsila Amaral, provavelmente nos mesmos moldes desse de Anita. Se esse fato ocorrer, podemos saúdá-lo como uma nova etapa na consolidação da arte no Brasil.

Convém não esquecer, ainda que seja até certo ponto secundário, mas o único prêmio de artista plástico brasileiro, com grande repercussão mundial na Bienal de Veneza, foi o outorgado ao desenho de Aldemir Martins, na década de 1960 do século passado.

Em relação à pintura de Anita Malfatti, também vamos encontrar não só uma apreciação estrita pela valorização do período "expressionista" da artista, mas mesmo uma depreciação franca de seus ensaios posteriores, principalmente por seus companheiros modernistas da Semana de Arte Moderna. Lembro-me, quando Rubem Borba de Moraes, em 1964, 1965, ao ministrar-nos umas aulas sobre biblioteconomia, no curso de pós-graduação organizado por Flavio Motta na FAU, em seu apartamento próximo, convidou-nos para ver sua biblioteca, e reiterava, em uma conversa extremamente rica, que Anita Malfatti tinha sido importante com suas pinturas alemãs e norte-americanas até 1924, mas com a ida à Europa, como pensionista do Estado, sua pintura perdera completamente o interesse, como contribuição cultural. Mas não é a mesma atitude, um pouco menos agressiva, é verdade, em relação à Tarsila? Depois de "Abapuru," em 1928, tudo que Tarsila fez não foi descaminho? E isso não foi sacramentado pelos inimigos declarados do "modernismo", mas por seus mais legítimos representantes.

Ora, essa atitude também é uma constante durante todo o século. Pois Belmiro de Almeida não é quase só conhecido por seu brejeiro e frívolo painel Arrufos, adquirido antes de a tinta ter secado completamente, pelo próprio governo federal, ainda no século 19, quando sua pintura densa do período pontilhista só mereceu um breve comentário do também excelente pintor José Maria dos Reis, em precioso livro sobre o artista. O exame, mesmo superficial, da obra de Belmiro de Almeida, ensina-nos que seu apuro no corte geométrico dos planos articulados de suas vistas urbanas, hauridos do mestre George Seurat foi um poderoso incentivo para uma nova reflexão (na época) sobre a decomposição cezanniana que resultou no cubismo. Entretanto, a crítica brasileira da época, com Arrufos, valorizava o quadro 0 importuno de seu amigo Almeida Junior, outro monumento da frivolidade de uma classe contente consigo mesma.

A pergunta que cabe, e deverá ser respondida por gente mais bem equipada, é o que perseguia a crítica brasileira de artes plásticas durante o século 20. Nada mais ilustrativo dessa postura do que a polêmica surgida em 1944, após a exposição de Lasar Segall, de 1943, promovida pelo Ministério de Educação e Saúde na capital da República, e minuciosamente documentada no capítulo "Fazer História" (p. 433 e seg.) do livro de Marta.

Contra a reivindicação de pioneirismo na implantação da arte moderna no Brasil, defendida para Lasar Segall por Rubem Navarra, Mario de Andrade 
protestou publicamente contra essa atribuição, insistindo sobre a prioridade da exposição de Anita em 1917 (contra a exposição de Segall em 1913), devido a nenhuma repercussão da segunda, enquanto a exposição de 1917 tivera a mais violenta manifestação de vontades desencontradas.

Ora, poder-se-ia argumentar com Rubem Navarra que a ausência de repercussão também é uma manifestação. Principalmente, se lembrarmo-nos não só de Belmiro, mas também de Seelinger, Eliseu Visconti, todos anunciadores (hoje sabemos) da repercussão no Brasil das novas correntes da arte contemporânea, não encontrando uma acolhida adequada no interior dos grupos de intelectuais atuantes na época. Ou o príncipe Zamoyski, que passou 30 anos no Brasil. O príncipe só voltou à Polônia (comunista) quando sentiu seu fim próximo e, como bom aristocrata, decidiu enterrar-se em seu solo católico e ancestral.

Boa parte da crítica praticada então pode ser resumida na afirmação que sua função seria, no caso dos críticos consagrados, querer explicitar o que os artistas deveriam querer. E os novos críticos desejavam que os artistas quisessem aquilo que eles (críticos) queriam que eles, artistas, fizessem.

Sobre quem era pioneiro ou não, a propósito de reivindicação de pioneirismo em arquitetura, Lucio Costa, nos meados da década de 1950 respondeu sarcasticamente: "arquitetura não é farwest". Aliás, arte também não é.

E também não é corrida de obstáculo.

Há, entretanto, na obra de Marta, uma afirmação, p. 375, que me parece exagero e também pode levar à confusão:

"Logo, o foco das principais manifestações da vanguarda artística brasileira se deslocaria para o Rio de Janeiro, com Portinari, "pintor oficial" e com a nascente arquitetura moderna."

Exagero porque, como vimos nos parágrafos anteriores, já desde o início do século havia sinais de um pensamento novo agitando os artistas plásticos da capital federal. E, na década de 1920, tanto Cícero Dias como Ismael Nery não dependeram diretamente da escandalosa Semana Paulista.

Também a expressão "pintor oficial" pode induzir a erro. Se, na década de 1940, Portinari recebeu encomendas "oficiais" como os painéis do Ministério da Educação e Saúde, e Pampulha, não podemos deixar de reconhecer que as encomendas oficiais nessas décadas foram, digamos assim, mais democraticamente distribuídas: Tarsila trabalhou para o Estado (por intermediação, inclusive, de Taunay) Helios Seelinger (Horto Florestal), bem como Arquimedes Memória (Ministério da Fazenda) ou Cristiano S. das Neves (Ministério da Guerra), obras muito mais custosas que as chamadas "oficiais" dos arquitetos modernos. Mais importante, embora miseravelmente incipiente, alguns artistas, mesmo violentamente discriminados, puderam realizar um trabalho nada desprezível, apesar de não-clamoroso. Não fosse o apoio decidido de uma parte da intelectualidade e Paulo Rossi Osir não poderia manter seu ateliê de azulejos "osirarte", e os magníficos azulejos de Portinari para o Ministério não existiriam, tampouco o painel extraordinário de fecho da parede de fundo da capela de São Francisco da Pampulha, com a "nacionalização" do Picasso de Guernica - um dos pontos altos da arte brasileira do período. Aliás, 
essa capela, com sua iluminação zenital dirigida para o painel de fundo do altar (abside?), parece ter sido concebida para destacar o afresco também de Portinari. Essas pinturas, essas edificações modernas não expressam o populismo do Estado Novo. Antes, foram impostas ao poder central nessas décadas (1940 e 1950) em um período de grande confusão política aqui e no mundo.

"Já vem o peso do mundo com suas fortes sentenças

Sobre a mentira e a verdade desabam as mesmas penas Apodrecem nas masmorras Juntas, a culpa e a inocência." (C. M.)

A exposição de 1917 e a Semana de Arte Moderna ocupam pouco mais de 100 páginas, sendo um dos pontos culminantes a crítica de Monteiro Lobato, posteriormente (1919) publicada no livro Idéias de Jeca Tatu, com o título Paranóia ou mistificação - A propósito da Exposição Malfatti.

0 curioso dessa estranha polêmica é que o autor concede altas qualidades à artista, como Marta transcreve, e, como exemplo, reproduzo:

"É um dever dizê-lo, porque poucos artistas se apresentaram com tantos elementos de triunfo como a senhorita Malfatti: seria profundamente lamentável ver perder-se num desvio de orientação estética uma organização artística como a dessa jovem pintora." ( $p$. 230)

Parece que as interpretações divergem ligeiramente, segundo Marta, mas também parece claro que 0 ataque não se dirigiu à artista, mas à "orientação estética" de alguns jovens artistas. Pois é a Oswald de Andrade que se dirige este parágrafo:

"Arte moderna, eis o escudo, a suprema justificação. Na poesia também surgem, às vezes, furúnculos desta ordem, provenientes da cegueira nata de certos poetas elegantes, apesar de gordos e a justificativa é sempre a mesma: arte moderna. Como se não fossem moderníssimos esse Rodin que acaba de falecer deixando após si uma esteira luminosa de mármores divinos..." (p. 208), como bem acentua Marta.

Mas às interpretações já firmadas apresento uma outra, apoiada, em primeiro lugar, em uma série de artigos de Sergio Milliet na revista Anhembi, de Paulo Duarte, nos quais estuda a poesia moderna paulista, especialmente dos poetas modernistas da Semana. Nesses artigos, Milliet chama a atenção para a rejeição de uma visão de um Brasil, prolongamento da tradição lusitana, e a acentuação da contribuição dos novos estrangeiros chegados há pouco, como os italianos (imigrantes). Essa colocação de Milliet se vê refletida nos contos de Alcântara Machado (Braz, Bexiga e Barra Funda) e nos primeiros contos de Mario de Andrade da década de 1920.

Em segundo lugar, em uma denúncia publicada na Folha de São Paulo pouco antes de morrer, escrita por Cláudio Abramo, na qual o respeitado jornalista afirmou, baseado em sua vida pessoal, o desprezo de Monteiro Lobato por mais um italianinho a solicitar-Ihe apoio, acusando-o de chauvinista e xenófobo. Talvez Abramo tivesse chegado em má hora, em momento difícil para 
Lobato, também um não muito feliz empresário. Mas, após esse alerta, podemos constatar, na obra do escritor, traços de desconfiança em relação aos imigrantes, das quais frações de sua classe eram pródigas (Ver Contos de Malazartes, de Mario de Andrade).

O senhor Francisco Assis Barbosa, em ensaio acrescentado à edição facsimilar, patrocinada pelo senhor José Mindlin, do primeiro livro infantil de Monteiro Lobato, reproduz parte do editorial do senhor Julio Mesquita, de 1916 em O Estado de São Paulo, proprietário da Revista do Brasil:

"O que há por detrás do titulo desta Revista e dos nomes que a patrocinam é uma coisa simples e imensa: o desejo, a deliberação, a vontade firme de constituir um núcleo de propaganda nacionalista. $\cdots$

Vivemos desde que existimos como nação, quer no Império quer na República, sob a tutela direta ou indireta, se não política ao menos moral do estrangeiro."

Mas essa constatação não pretende insinuar que a "oligarquia cafeeira" inteiriça seria chauvinista ou xenófoba. Mesmo porque as poupanças do café, em grande parte, eram absorvidas desde 1860 pela grande indústria têxtil que se instalava e pelas ferrovias. Estas exigiram a criação da Escola Politécnica e do ensino técnico, elementos necessários para o desenvolvimento industrial paulista. Também não encontrou guarita, em toda a "oligarquia cafeeira", a caricatura predominantemente paulista do fascismo italiano no Brasil. Ao contrário, Monteiro Lobato, até onde se sabe, manteve distância do integralismo, seu sigma e anauê. Quanto à sua visão de artes plásticas, à distância de oito décadas e os documentos disponíveis, só se pode conjecturar que o escritor, como a imensa maioria dos brasileiros, inclusive seus intelectuais, alienados do pensamento moderno em sua interpretação da realidade, só podia se apoiar na ideologia dominante no Brasil, escombro da visão de mundo jesuítica, levemente trabalhada pelo positivismo de Augusto Comte.

Apesar dos textos expostos com grande firmeza, nosso escritor era tão inseguro e despreparado quanto seus opositores mais jovens. Perceberia ele que os desenhos de Voltolino, seu ilustrador de eleição para seus primeiros livros infantis, estava mais próximo de Anita do que dos ilustradores futuros?

Essa situação contraditória se positiva ainda mais quando se verifica que seu sócio desde 1917 na Revista do Brasil, Paulo Prato, é o mesmo "barão do café" que iria patrocinar a Semana de Arte Moderna no Municipal em 1922. Mesmo assim, podemos dizer que a polêmica, tendo como pretexto a jovem artista paulistana, serviu para distanciar dois grupos de nacionalistas: o primeiro, caracterizado por um nacionalismo cujo chauvinismo e xenofobia iriam cada vez mais predominar, culminando na ideologia separatista de 1932 e a ideologia integralista de 1935 e 1937. O outro grupo nacionalista, sob certos aspectos ainda vigente, ecumênico em relação aos "novos brasileiros", cada vez mais libertário, inclusive absorvendo, pelas correntes socialistas dos vários matizes, a incorporação do moderno pensamento crítico - Sergio Buarque de Holanda (Max Weber), Caio Prado Junior (Marx e Engels), Gilberto Freyre (a moderna antropologia norte-americana), Afonso Arinos (Conde Sforza, Benedetto Croce), Jose Honório Rodrigues (Benedetto Croce). 
Em relação à Anita, teria o grande escritor se arrependido de seu inoportuno e impertinente ataque? Difícil é saber, sem documentos ou testemunhos do tempo, principalmente hoje, que a maior parte de seus contemporâneos já desapareceu. Principalmente porque a distância estética entre Lobato e seus modernistas opositores não era tão grande assim. Se Oswald de Andrade reconheceu, generosamente, que Urupês está na base, na origem da atitude crítica de alguns modernistas, por outro lado, as irreverências modernistas não terão contaminado Lobato, principalmente na boneca Emilia, da literatura infantil, que, de mamulengo (boneco mudo e desengonçado) da primeira história, evolui para ser a irreverente e imaginosa personagem central das últimas aventuras?

Difícil é saber, mas as pessoas que podiam influir, na década de 1920, sobre a decisão de outorgar, em 1924, o "pensionato artístico" do Estado, a Anita Malfatti, mais do que concernente à mesma "oligarquia", pertenciam, como dona Olívia G. Penteado, à mesma família do sócio de Monteiro Lobato (Paulo Prado) e, provavelmente, seus amigos e admiradores. Ele não saberia nada a respeito dessas cogitações prévias? Ou, quem sabe, não teria dado seu assentimento? O prêmio de Pensionato Artístico em Paris para Anita Malfatti parece mais um desagravo, tendo em conta sua idade, do que esperança em jovem talentosa e promissora. O pensionato artístico seria, genericamente, alvo de pilhérias em 1928, na obra Macunaíma, de Mario de Andrade. Por outro lado, tudo isso tem pouca importância: a cada pessoa sua sentença; e à humanidade, seu destino.

Não podemos deixar de assinalar o surgimento de artistas oriundos das classes próximas ao proletariado, principalmente a partir dos anos 30, e, com eles, "críticos de classe", os quais, partindo dessa época procuraram estigmatizar o modernismo como um entretenimento da alta burguesia paulista opressora e prepotente. Sem dúvida, os modernistas mais em evidência eram bem abonados, como Oswald de Andrade e Tarsila, e a Semana foi patrocinada por Paulo Prado e Olívia G. Penteado, mas a obra posterior da maior parte deles não confirma essa postura hedonista que se Ihes queria impingir. Muito ao contrário, foram esses mesmos representantes da elite brasileira que acolheram esses artistas, e mesmo suas reivindicações (legítimas) de ascensão social: Carlos Prado, Mario Pedrosa, Caio Prado, Oswald de Andrade, Tarsila, Mario de Andrade e Anita.

O livro de Marta nos mostra, com sua rica documentação, que ela se desvencilhou com isenção dos pré-julgamentos, tanto dos detratores do "modernismo" como de seus cultores:

"Mas entre sua produção variada como técnica e temática, havia linhas contínuas: as tabuinha, as naturezas mortas e os retratos. A pintora executou muitos retratos, fossem de familiares, alunos e amigos, ou (de encomenda). Foi no retrato que Anita Malfatti conciliou melhor subsistência e arte, nos anos 30. "Se não eram mais obras de vanguarda - no sentido que o foram 'O homem amarelo' e $A$ mulher de cabelos verdes - são obras bem realizadas e merecem ser estudadas." (p. 418) 
(1) Essa resenha foi anteriormente publicada na Revista IEB-USP, em

2007. A revista $P O ́ S$ a reproduz em homenagem póstuma à Profa. Dra. Marta Rossetti Batista,

que compôs seu Conselho Editorial de 2001 a 2007.
Não só essa afirmação nos parece básica para qualquer apreciação futura, como, tudo indica, para uma apreciação mais isenta de toda a obra da artista: na exposição de 1917, ao lado do excelente retrato do pintor Baylinson (Retrato de Bajley), outros desenhos e caricaturas parecem ser meros exercícios escolares.

Aliás, toda a obra de Anita merece uma avaliação possível, se for organizada uma grande retrospectiva da pintora e também uma homenagem à sua mais afetuosa biógrafa. Marta já não está entre nós, e só me cabe, neste momento, oferecer sua vida para os jovens como espelho e iluminação, fazendo como ela fez e serve-nos de modelo: trabalhou cotidianamente e com todo o seu afeto discreto, para o melhoramento político-social do homem ${ }^{1}$.

\section{Júlio Roberto Katinsky}

Professor titular do Departamento de História e Estética do Projeto, professor-orientador do curso de pós-graduação da FAUUSP.

Rua Maranhão, 88. Higienópolis

01240-000 - São Paulo, SP

(11) $3257-7688$

jrkatinsky@uol.com.br 